\title{
AMENDMENTS
}

\section{Author Correction: GWAS of lifetime cannabis use reveals new risk loci, genetic overlap with psychiatric traits, and a causal effect of schizophrenia liability}

Joëlle A. Pasman (D), Karin J. H. Verweij, Zachary Gerring, Sven Stringer (iD, Sandra Sanchez-Roige, Jorien L. Treur, Abdel Abdellaoui, Michel G. Nivard (D), Bart M. L. Baselmans, Jue-Sheng Ong (D), Hill F. Ip (D), Matthijs D. van der Zee, Meike Bartels (D), Felix R. Day DD, Pierre Fontanillas, Sarah L. Elson, the 23andMe Research Team, Harriet de Wit, Lea K. Davis D, James MacKillop (D), The Substance Use Disorders Working Group of the Psychiatric Genomics Consortium, International Cannabis Consortium, Jaime L. Derringer, Susan J. T. Branje, Catharina A. Hartman, Andrew C. Heath, Pol A. C. van Lier, Pamela A. F. Madden, Reedik Mägi, Wim Meeus, Grant W. Montgomery ID, A. J. Oldehinkel (D), Zdenka Pausova, Josep A. Ramos-Quiroga, Tomas Paus, Marta Ribases (D), Jaakko Kaprio (iD, Marco P. M. Boks DiD, Jordana T. Bell, Tim D. Spector, Joel Gelernter D, Dorret I. Boomsma, Nicholas G. Martin, Stuart MacGregor (D), John R. B. Perry, Abraham A. Palmer (iD, Danielle Posthuma (D), Marcus R. Munafò D, Nathan A. Gillespie, Eske M. Derks (iD) and Jacqueline M. Vink (D)

Correction to: Nature Neuroscience https://www.nature.com/articles/s41593-018-0206-1, published online 27 August 2018.

In the version of this article initially published, several occurrences of the word 'schizophrenia' should have more accurately been worded as 'liability to schizophrenia' or 'schizophrenia risk', including in the title. Specifically, in the dataset used for the genome-wide association meta-analysis of cannabis use, only a small proportion of the participants will actually have been diagnosed with schizophrenia. Therefore, it is more precise to say that the analyses reported in the paper show that the 'liability to schizophrenia' (rather than schizophrenia itself) leads to cannabis use. Additionally, there was a typo in the original report. The genetic correlation is very marginally higher and more significant. Congruent with Supplementary Table 6, the observed correlation is $r_{g}=0.25\left(\right.$ s.e. $\left.=0.03, P=5.81 \times 10^{-15}\right)$.

\section{Publisher Correction: L3MBTL1 regulates ALS/FTD-associated proteotoxicity and quality control}

Jiayin Lu, Goran Periz (D), Yu-Ning Lu, Qing Tang, Yang Liu, Tao Zhang, Yajas Shah, Ravi Thombre, Reham Aljumaah, Weixin Li, Jelena Mojsilovic-Petrovic, Yon Ji, Kenji Johnson, Robert Kalb and Jiou Wang (D)

Correction to: Nature Neuroscience https://doi.org/10.1038/s41593-019-0384-5, published online 6 May 2019.

In the version of this article initially published online, in Fig. 4f, the leftmost bar (CTRL) in the left graph was missing. The error has been corrected in the print, PDF and HTML versions of this article.

Original

f

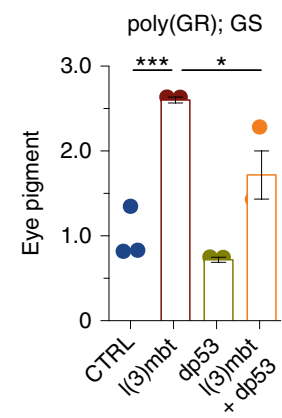

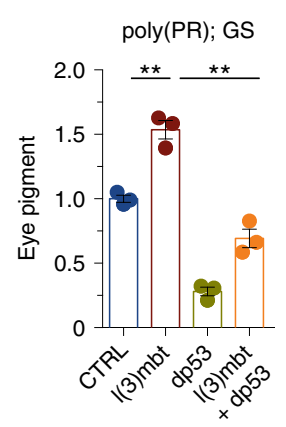

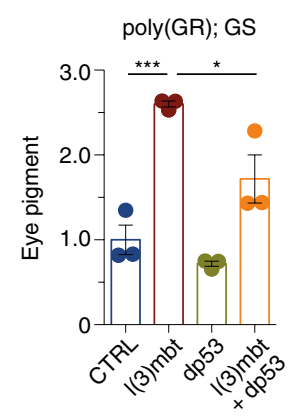

Fig. 4 | Original and Corrected. 